مقايسه اثر دو روش يُ حلقى (يك خيس شله با سالين ويك خيس شله

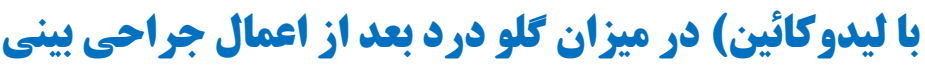

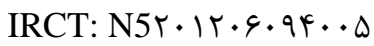

حمزه حسين ز/ده ، حسن محملى يور انورى '، خسرو كلاهدوزان "، فرانك شيخ منزه

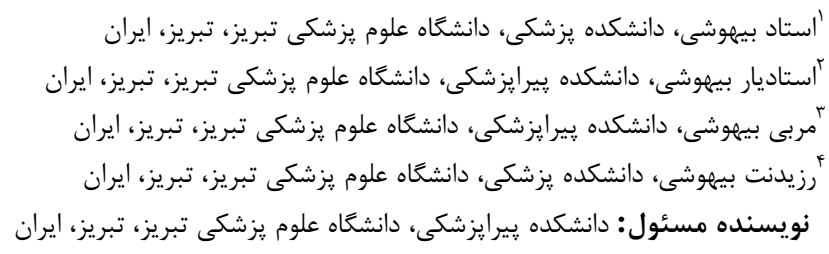

يست الكترونيك: yahoo.com

ك5بر

زمينه و اهداف: كلودرد يكى /ز عوارض شايع و ناخوشايند بى هوشى است كه اغلب به ننبال اكستوباسيون

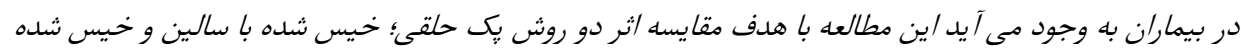

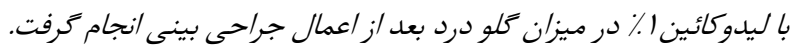

مواد و روشى كار: در يك كار آزمائى بالينى دو سوكور تصادفى شده تعداد •ع بيمار در محدوده سنى •V-11 سال باكلاس I-II-III ASA نيازمند عمل جراحى انتخابى بينى، در دو كروه قرار Fرفتند، در كروه اول /ز كاز خيس

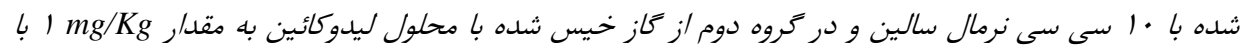

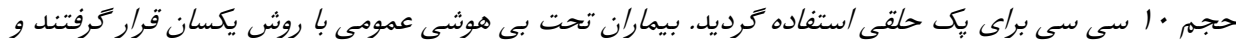

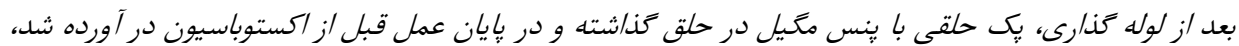

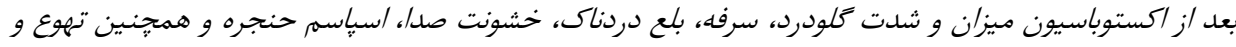
استفراغ مورد بررسى و مقايسه قرار عرفت.

يافته ها: بين دو كروه /ز لحاظ وزن، قد، جنس، سن و طول مدت جراحى و نوع عمل جراحى تفاوت معنى دارى وجود نداشت. /ز نظر كلو درد تفاوت معنى دارى بين دو كروه ليدوكايين وكروه بِاسبو ديله نشد.

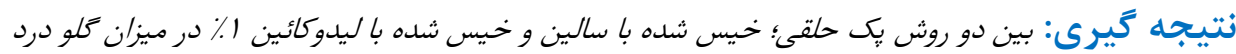
بعل /ز عمل تنفاوتى ديله نشل. وازه هاى كليدى: پَى حلقى، جراحى بينى، ليدوكايين، كلودرد

DOI: http://journal.nkums.ac.ir/article-1-1043-fa.html

Cite this article as: Hosseinzadeh H, Mohmmadi Pour Anvari H, kolahdouzan K, Sheikhmonazzah F. Comparison of the effect of two pharyngeal packing methods (wet pack with saline and wet pack with lidocaine) on postoperative sore throat after nasal surgery. JNKUMS. 2017; 8 (4) :623-632 
با توجه به اينكه در مورد ميزان ايجاد كلودرد به دنبال

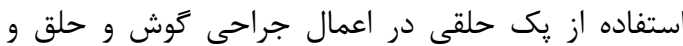

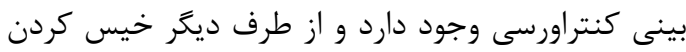

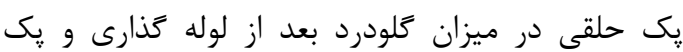
كذارى باعث كاهش كلودرد مى شود و با توجه به اينكه

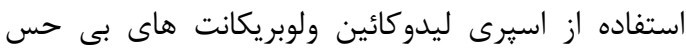

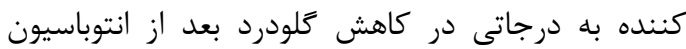

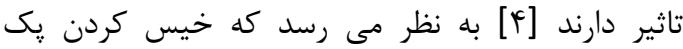
حلقى با محلول ليدوكائين باعث كاهش قابل توجهى در دران

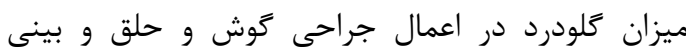

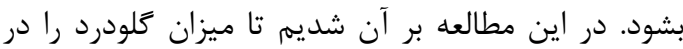

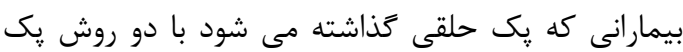

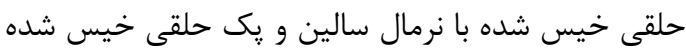
با محلول ليدوكائين 1\% با را مقايسه نمائيم.

\section{روش كار}

بعد از اخذ موافقت و تصويب كميته منطقه اى اخلاق دانشخاه كد كارآزمايى بالينى در زير عنوان نوان نوشته شود در 4.

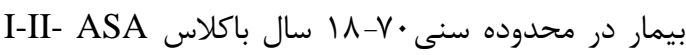

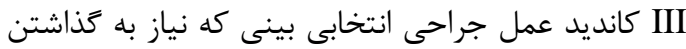

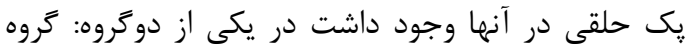

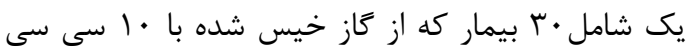

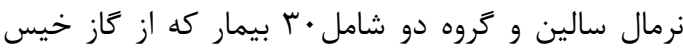

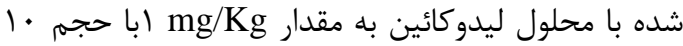
سى سى براى يك حلقى استفاده گرديد قرار كرفتيند. معيارهاى ورود به مطالعه شامل تمامى بيماران كانديد

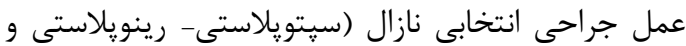

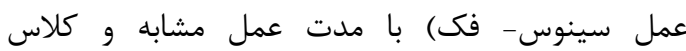
مالامياتى I-II بود و بيماران با راه هوايى مشكل، كلاس مالامياتى بالاتر از II لارنكوسكويى طول كشيده بيشتر

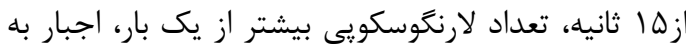

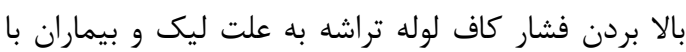
كلودرد قبل از عمل از مطالعه حذف شدند. همه بيماران تحت بى هوشى عمومى با روش يكسان با فنتانيل

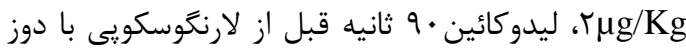
_ _

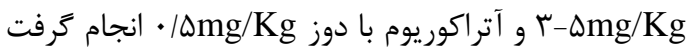

بى هوشى عمومى باعث عوارض زودرس و ديررس در بيمار مى شود. يكى از شايع ترين عوارض كلون بلودرد است كه

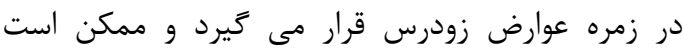

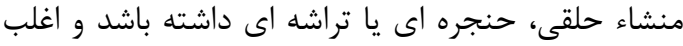
به دنبال خارج كردن لوله تراشه بيماران به وجود مى آئ آيد

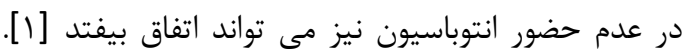
در بى هوشى با ماسك بدون انجام لوله كَذارى ناى وحتى تئى در روش نخاعى وجود كلودرد بعد از بيهوشى نيز كزارش

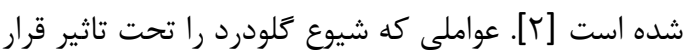
مى دهند شامل سطح تماس تراشه وكاف (تراكئيت)،

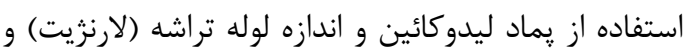

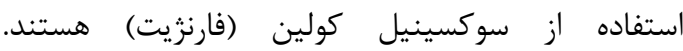
احتمالا"در لوله هايى كه ارتباط كاف با تراشه بيش تر

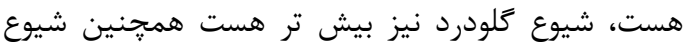

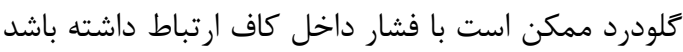

اخرجه كلودرد يك عارضه جانبى خفيف بعد از بى هوشى

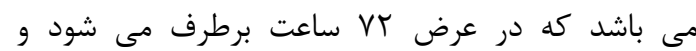

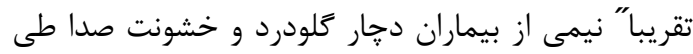

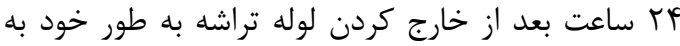

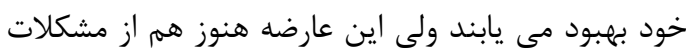

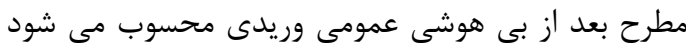

در اعمال جراحى گَوش و حلق و بينى در بعضى كشورها

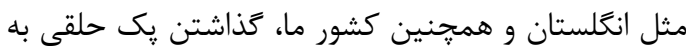
دنبال لوله كذارى داخل تراشه معمول است و اين كار جهت كاهش بلعيدن خون و ورود خون به داخل مرى و

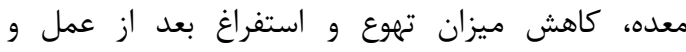
همجنين براى جلوكيرى از اسبيراسيون خون و ترشحات

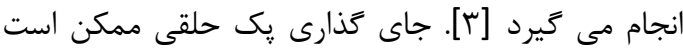

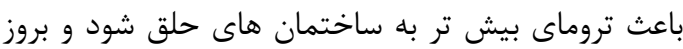

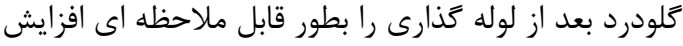

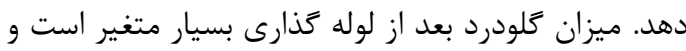

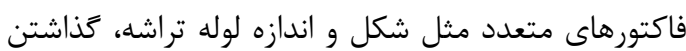

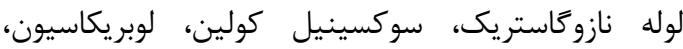

استفاده از يك حلقى نقش دارند [ب]. 


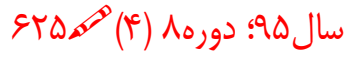

مجله دانشخاه علوم يزشكى خراسان شمالى

روش تصادفى سازى به صورت بلوك هاى پِّ و يِي

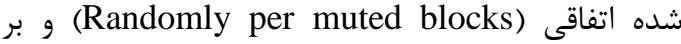

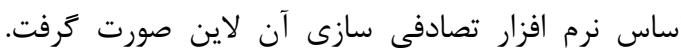
حجم نمونه با استفاده از نرم افزار سايت http://www.randomizer.org و با استفاده از

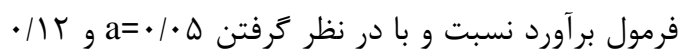

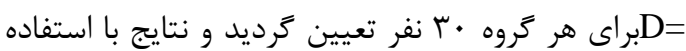
از آزمون آمارى تى مستقل و طرح اندازه كيرى هاى مكرر

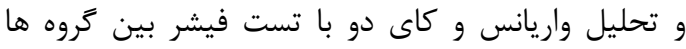

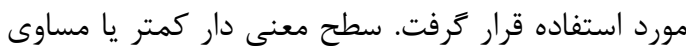

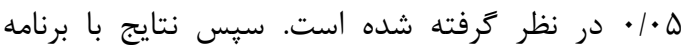
آمارى SPSS16 تجزيه و تحليل شد.

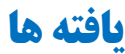

در اين مطالعه تعداد •9 بيمار در دو گروه ليدوكائين و

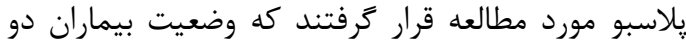

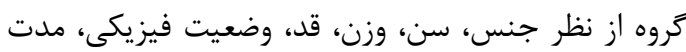

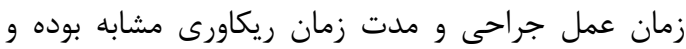

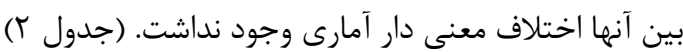

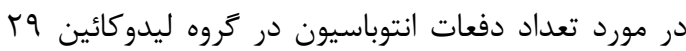
نفر فقط يكبار و يك نفر دو بار انتوبه شد و در در كروه يلاسبو از •r نفر qج نفر يكبار و يك نفر سه بار انتوبه
و جهت نكَهدارى بى هوشى از روش TIVA با انفوزيون يرويوفول و رمى فنتانيل استفاده كرديد.

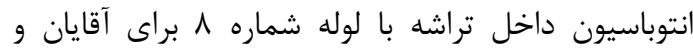
شماره V براى خانم ها توسط يك متخصص مجرب انجام كرفت. بعد از تاييد لوله كذارى توسط سمع و كاينوكرام

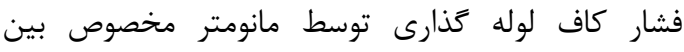

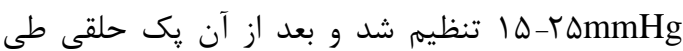
لارنكوسكويى با بنس مخيل در حلق كذاشته شد. انتخاب نوع يُ حلقى خيس شده توسط فرد ديكرى انجام كرفت

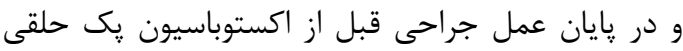

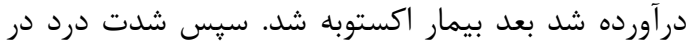

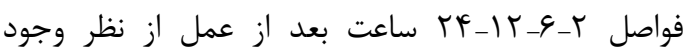
كلودرد با روش فول خط كش •ا سانتى مترى كه قبلا" به مريض آموزش

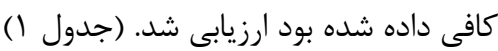

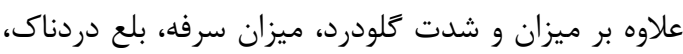
خشونت صدا، اسياسم حنجره و همجنين تهوع و استفراغ

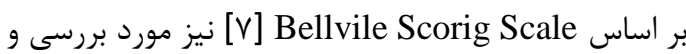
مقايسه قرار كرفت. لوله تراشه مصرفى در تمامى بيماران

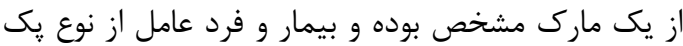
حلقى به كار رفته اطلاعى نداشتند.

جدول ا: تعريف شدت كلودرد، خشونت صدا و بلع دردناك با توجه به معيار اندازه كيرى VAS

\begin{tabular}{|c|c|c|c|c|}
\hline سرفه & بلع دردناك & خشونت صدا & شدت كلودرد & نمره(VAS) \\
\hline عدم وجود سرفه & عدم وجود بلع دردناك & عدم وجود خشونت صدا & عدم وجود كلودرد & · \\
\hline \multirow{2}{*}{ سرفه خفيف } & بلع دردناك خفيف & خشونت صداى خفيف كه توسط & درد خفيف فقط در پاسخ به سوال & r.t.l \\
\hline & & خود بيمار اظهار مى شود & بدون هيج علامت رفتارى & \\
\hline \multirow[t]{2}{*}{ سرفه متوسط } & بلع دردناك متوسط & خشونت صداى متوسط كه توسط & درد متوســط در ياسـخ بـه سـوال بــا & $9 . b_{0} f^{\mathrm{r}}$ \\
\hline & & فرد معاينه كننده آشكار مى شود & علائم رفتارى & \\
\hline \multirow[t]{2}{*}{ سرفه شديد } & بلع دردناك شديد & خشونت صدا شديد بصورت عدم & درد شديد بصورت پاسخ شديد ََفتارى از & $V_{(1,9.9 .1} \cdot$ \\
\hline & & صحبت كردن & طرف بيمار & \\
\hline
\end{tabular}




\begin{tabular}{|c|c|c|c|}
\hline $\mathrm{P}$ & گروه يلاسبو & كروه ليدو كائين & \\
\hline.$/ 1 F F$ & $18 / 14$ & $11 / 19$ & 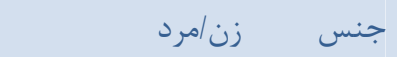 \\
\hline$\cdot 110$ & $r \Lambda / \varepsilon \Lambda \pm \Lambda / \& r$ & $r \varepsilon / V \Psi \pm \Delta / 9 q$ & سن( سال) \\
\hline ש & 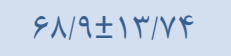 & $g Y \pm|r / V|$ & وزن(Kg) \\
\hline . Kt & $199 / 9 \mathrm{~V} \pm \mathrm{V} / \mathrm{r}$. & $|\Delta N /| V \pm V / 9 \mid Y$ & قد(Cm) \\
\hline \multirow[t]{3}{*}{$\cdot / T T A$} & $\cdot / 1 / r \Lambda$ & $1 / 1 / T V$ & | II ASA AS وضعيت فيزيكى \\
\hline & $1 V \cdot / 0 \cdot \pm 98 / 94$ & $|\Lambda \cdot| \Lambda V \pm V Y / A V$ & مدت زمان عمل جراحى(دقيقه) \\
\hline & $r \Delta / g T \pm \Delta / \wedge \Delta$ & $r \varepsilon / 1 \cdot \pm r / q$. & مدت زمان ريكاورى(دقيقه) \\
\hline
\end{tabular}

همجنين لرز بعد از عمل در تروه ليدوكائين در 9 نفر

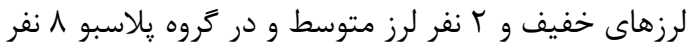

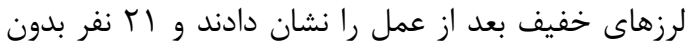

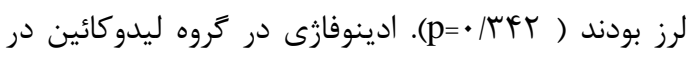

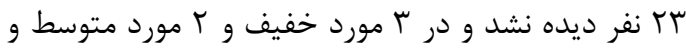

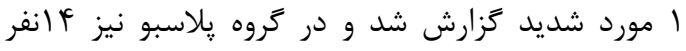

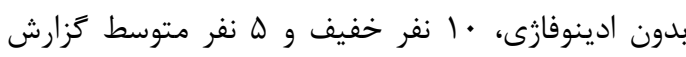

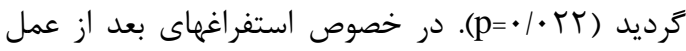

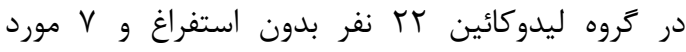

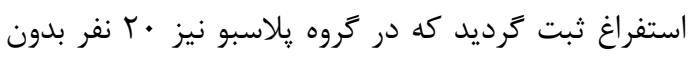

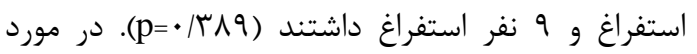
كلودرد بعد از عمل در كروه ليدوكائين · ب نفر از افراد

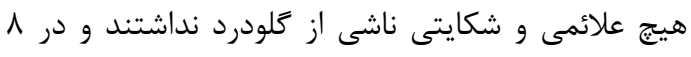

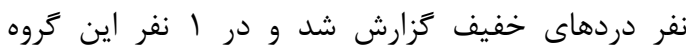

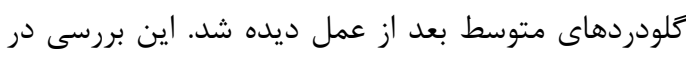

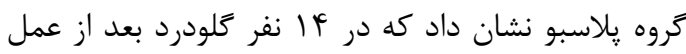

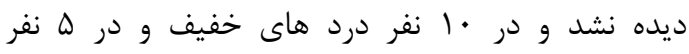
كلودردهاى متوسط بعد از عمل كزارش شد كه براساس

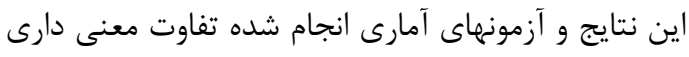

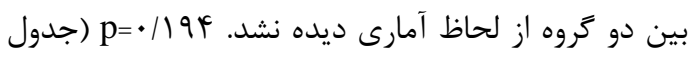

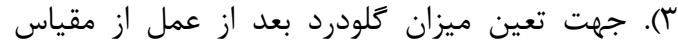

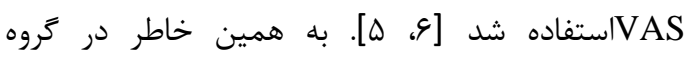

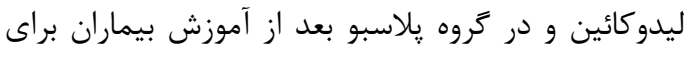

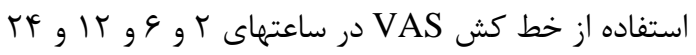

كرديد كه اين دو بيمار با توجه به معيار هاى خروج از

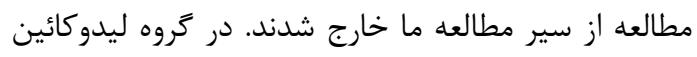

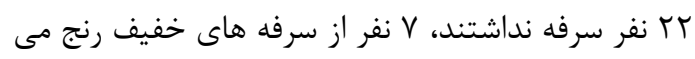

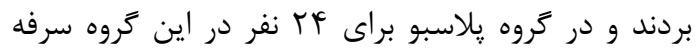

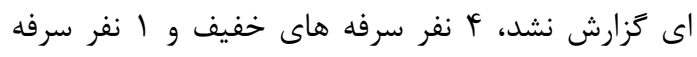

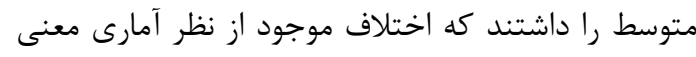

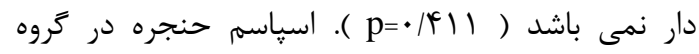
ليدوكائين از وج نفر مورد مطالعه در دو مورد ديده شد كه آنه

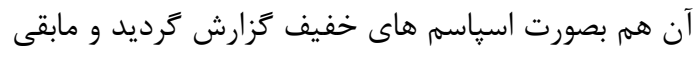

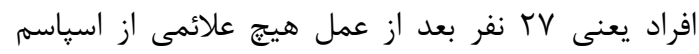

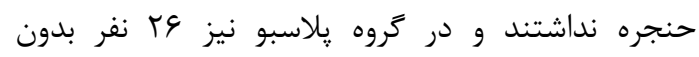

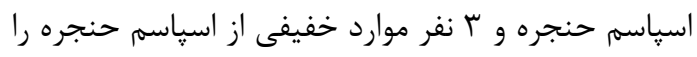

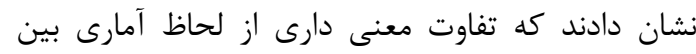

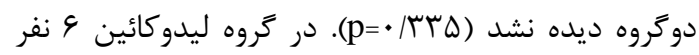

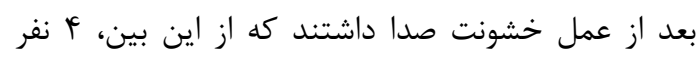

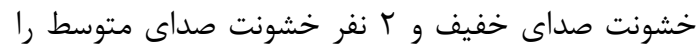

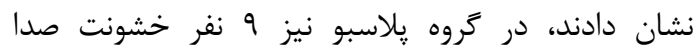

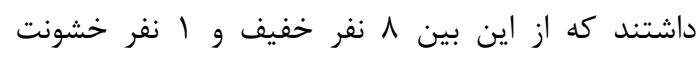

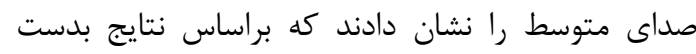

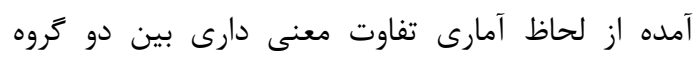

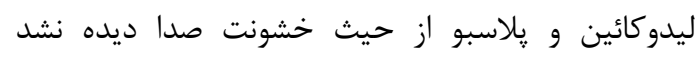

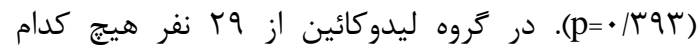

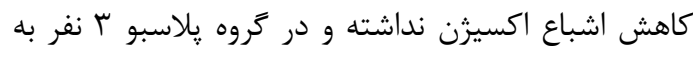

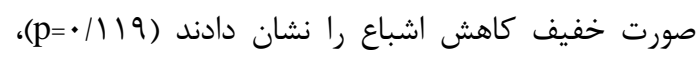


جدول سا: مقايسه دو گروه از نظر سرفه، اسياسم حنجره، خشونت صدا، كاهش اشباع اكسيرن، لرز بعد از عمل، ادينوفازى، كلودرد و استفراغ P-value $\quad$ (P)

\begin{tabular}{|c|c|c|c|}
\hline.$/ 411$ & $\begin{array}{c}r f \\
F \\
1\end{array}$ & $\begin{array}{l}\text { TY } \\
\text { V } \\
-\end{array}$ & سرف سرف سرفه \\
\hline \multirow[t]{3}{*}{$\cdot \pi r \Delta$} & & & اسياسم حنجره \\
\hline & rq & TV & عدم اسياسم \\
\hline & r & $r$ & اسياسم خفيف \\
\hline \multirow[t]{4}{*}{ r } & & & خشونت صدا \\
\hline & $r \cdot$ & r & عدم وجود خشونت \\
\hline & $\wedge$ & r & خشونت خفيف \\
\hline & 1 & $r$ & خشونت متوسط \\
\hline \multirow[t]{3}{*}{.1119} & & & كاهش اشباع اكسيزن \\
\hline & rq & rq & عدم وجود كاهش \\
\hline & r & - & كاهش خفيف \\
\hline \multirow[t]{4}{*}{. MET } & & & لرز بعد از عمل \\
\hline & rI & rI & عدم وجود لرز \\
\hline & $\wedge$ & 9 & لرز خفيف \\
\hline & - & r & لرز متوسط \\
\hline \multirow[t]{5}{*}{. } & & & ادينوفارى \\
\hline & 14 & r & عدم وجود ادينوفازى \\
\hline & $1 \cdot$ & $r$ & ادينوفازى خفيف \\
\hline & $\Delta$ & $r$ & ادينوفازى متوسط \\
\hline & - & 1 & ادينوفازى شديد \\
\hline \multirow[t]{4}{*}{.1194} & & & كلودرد \\
\hline & If & $r$. & عدم وجود كلودرد \\
\hline & 1. & $\wedge$ & حلودرد خفيف \\
\hline & $\Delta$ & 1 & كلودرد متوسط \\
\hline \multirow[t]{3}{*}{.1119} & & & استفراغ \\
\hline & $r \cdot$ & rr & عدم استفراغ \\
\hline & 9 & V & استفراغ خفيف \\
\hline
\end{tabular}


نمودار ا: يراكندگى نمره VAS در دو گروه مورد مطالعه

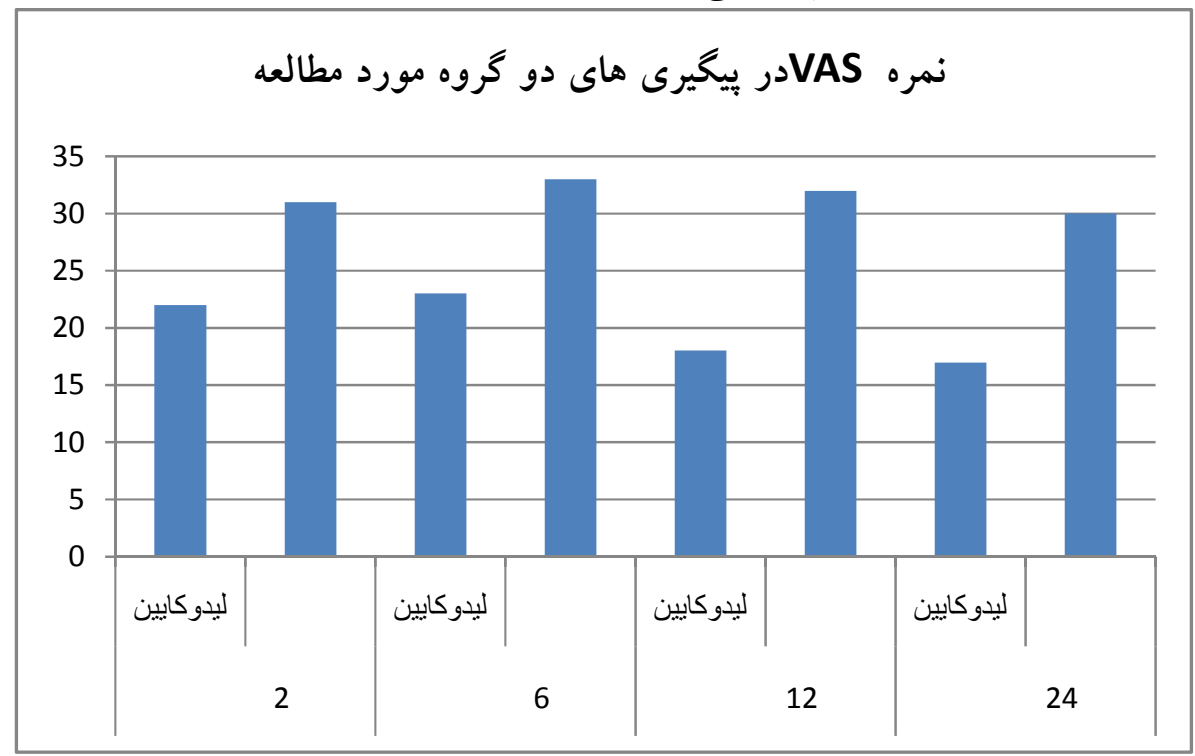

بى هوشى با ماسك بدون انجام لوله كذارى ناى و حتى در

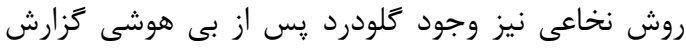

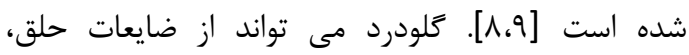

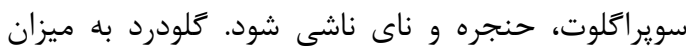

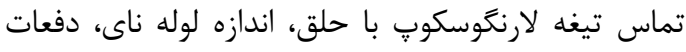

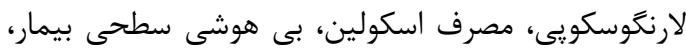

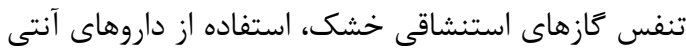
كولينرزيك و كاربرد راه هاى هوايى دهانى-حلقى بستخى

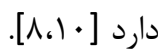
در مطالعه دكتر خضرى كه در مورد مقايسه ميزان كلو

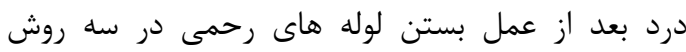

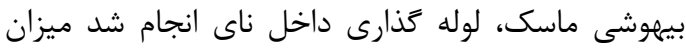

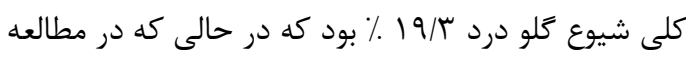

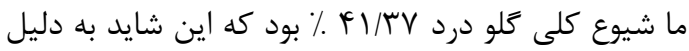

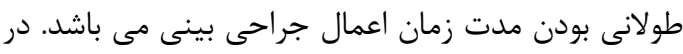

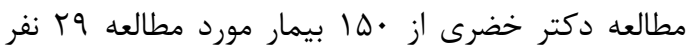

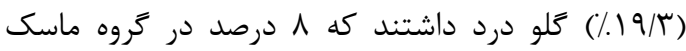

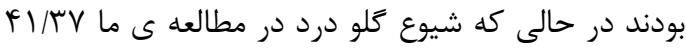

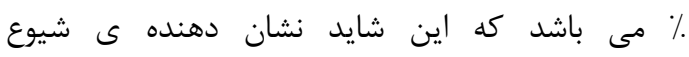

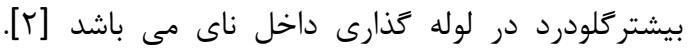

ساعت بعد از عمل ميزان درد ثبت و گزارش كرديد. شدت درد در ساعتهاى مختلف پِيگيرى شد كه با توجه به

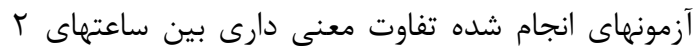

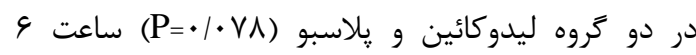

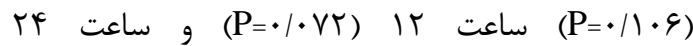
(P=•/.9Y)

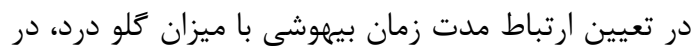

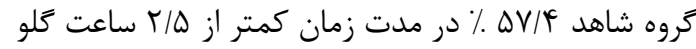

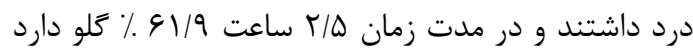

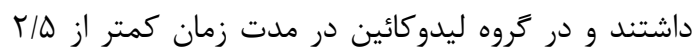

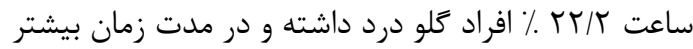

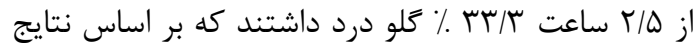

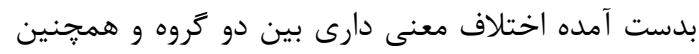
داخل گروهى مشاهده نشد و در نتيجه بين كلو درد و ورد مدت زمان بيهوشى ارتباطى بدست نيامد.

براساس نتايج بدست آمده از اين مطالعه تفاوت معنى

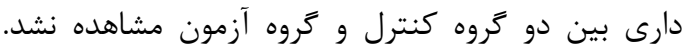

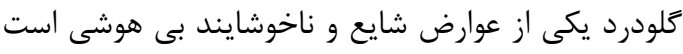
كه اغلب به دنبال اكستوباسيون به وجود مى آنى آيد. البته در هر 
و خشن باعث آسيب به مخاط حلق و حنجره مى شود

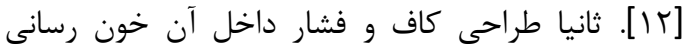

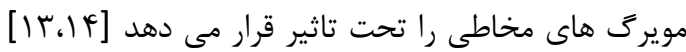
ثالثا تماس لوله تراشه با طناب هاى صوتى و دان ديواره خلفى حلق منجر به خيز يا آسيب به اين ناحيه مي شود

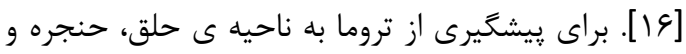
تراشه روش هاى متنوع زير ييشنهاد شده است فشار كم

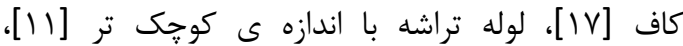

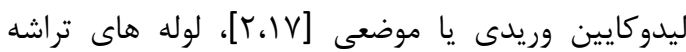

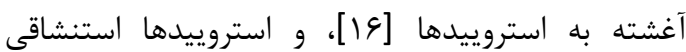

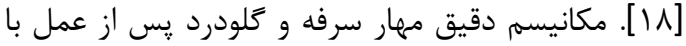
مصرف ليدوكايين هنوز مشخص نيست مهار فيبرهاى تحريك كننده ى C راه هوايى كه باعث كاهش نور و

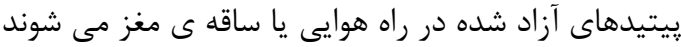

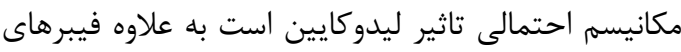

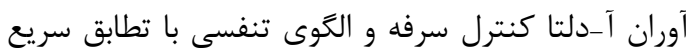
كيرنده هاى تجريكى و كيرنده هاى كششى ريوى با تطابق

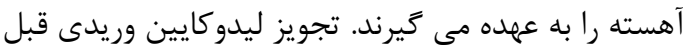

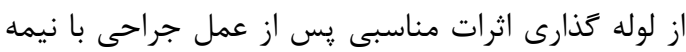
عمر پِلاسمايى r ساعت ايجاد مى كند [19]. احتمالاً حساسيت راه هوايى شبيه وضعيت رخداد درد مى باشد إند رخداد درد در اين حالت مى تواند بدون وجود تحريك يانيا

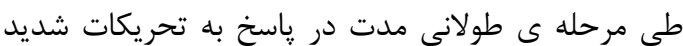
يس از ايجاد حساسيت به دنبال آستانه

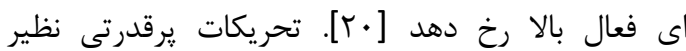
لارنكوسكويى با حركت لوله تراشه با تحريك فيبرهاى حسى C و توليد نوروييتيدهاى عصبى منجر به كلودرد و سرفه يس از عمل جراحى مى شود. ليدوكايين احتمالاً نه

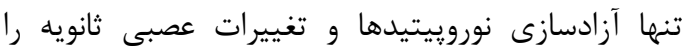
كاهش مى دهد، بلكه مهار مستقيم و مركزى اين دارو نيز

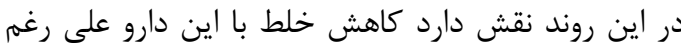
تاثير مشابه آن بر كلودرد و سرفه از طريق آنائ فيبرهاي حسى Cبارز نيست [إr]. تغييرات پاتولوزيكى در مخاط حنجره و تراشه به دنبال لوله كذارى رايج در ايجاد خشونت صدا يس از عمل جراحى نقش دارد اين تغييرات به صورت از دست رفتن إيى تليوم مخاطى، خيزو هماتوم

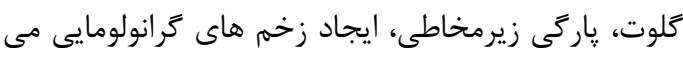

فنسى' و همكاران كزارش نمودند كه يك حلقى خشك

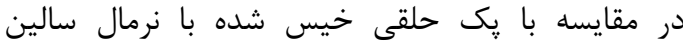
تروماى بيش ترى به ساختمان حلق وارد مى كند و و باعث

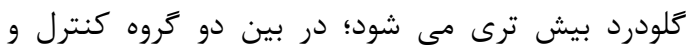

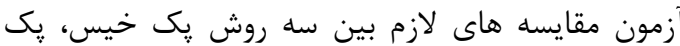

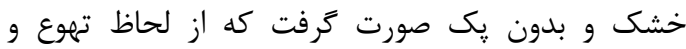
استفراغ رابطه معنى دارى كزارش نشد [11]. باشا؟ و و

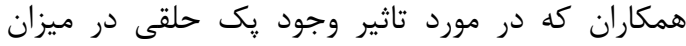

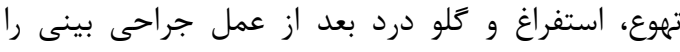

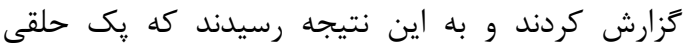

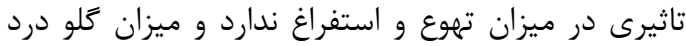

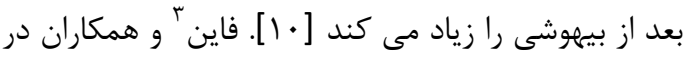
مطالعه خود كه شامل •9 بيمار بود كه اين جامعه را به له اله كروه تقسيم كردند، كروه اول به صورت لوله نازال تراكئال

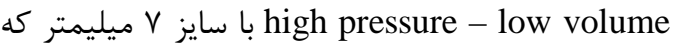
كاف ير شده بود و يك حلقى وجود داشت و در گروه دوم سايز F/V ميليمتر و كاف ير نشده بود و ريك حلقى وجود

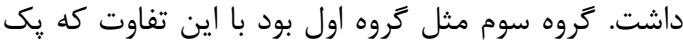

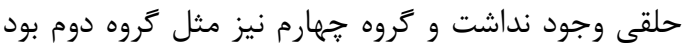

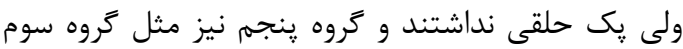

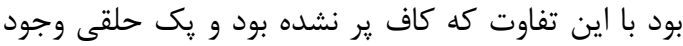

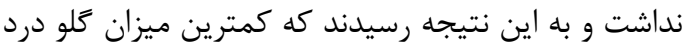
در گروهى مى باشد كه يَى حلقى ندارد و كاف ير نشده

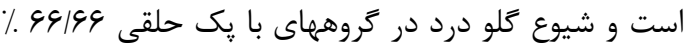

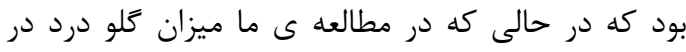

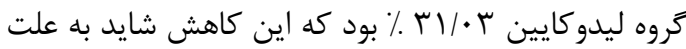

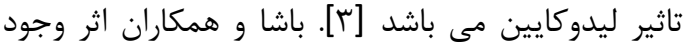

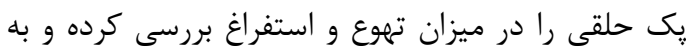
اين نتيجه رسيدند كه يك حلقى تاثيرى در ميزان تهوع و

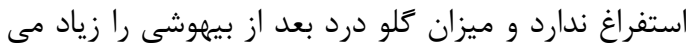

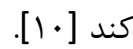
كلودرد ناشى از عوامل متعددى است اولا لارنكوسكويى و

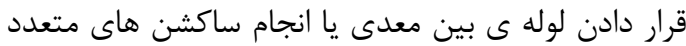

1-Fennesssy

2-Basha

3-Fine 


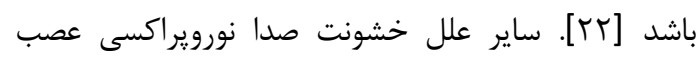

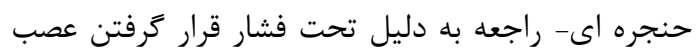
فوق بين غضروف هاى كريكوييد و آريتنوييد ناشى از فشار فئ دار

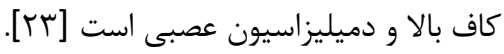

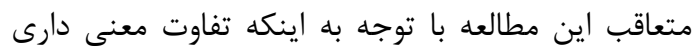

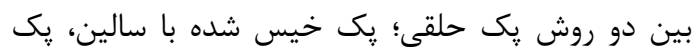

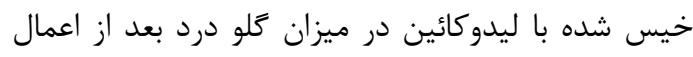

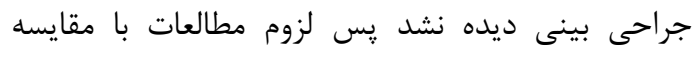

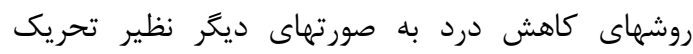

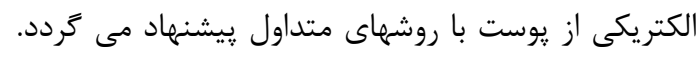

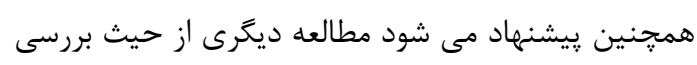

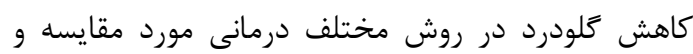
تفسير قرار گيرد. نتيجه تيرى

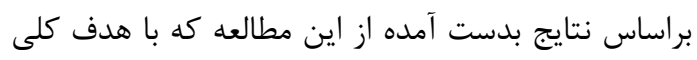

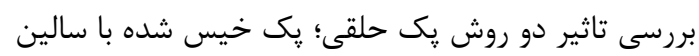

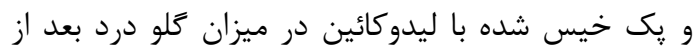

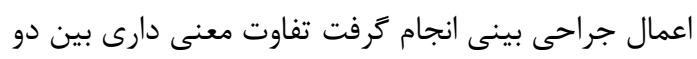

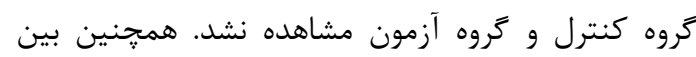

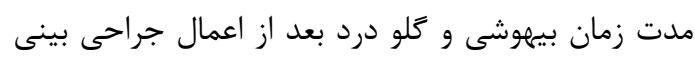
تفاوت معنى دارى ديده نشد.

\section{تشكر و قدر مانى معى دري}

از معاونت محترم يزوهشى دانشكاه علوم يزشكى تبريز كه با

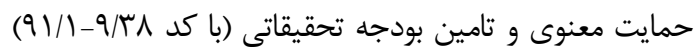
ما را در طول اين طرح يارى فرمودند سياسكزاريم. 


\section{References}

1. M Ebtehaj, A Jahangiri-fard,H Kayalha,A Javadi , T Karimzadeh, Effect of $10 \%$ lidocaine spray on postoperative sore throat, JQUMS 2010;14(2),36-41

2. M Khezri, Comparison of sorethroat incidence after tubal ligation in three anesthesia techniques, The Journal of Qazvin Univ.of Med.Sci 2003;27,61-64

3. Fine J, Kaltman S, Bianco M, Prevention of sore throatafter nasotracheal intubation, Journal of Oral and Maxillofacial Surgery 1988; 46, 946-7.

4. MR Safavi,A Honarmand, Comparison of beclomethasone inhalation and Iv lidocaine in prevention of post operative sorethroat, Journal of Zanjan University.of Med.Sciences 2009; 15: 1120

5. McCaffery M, Beebe A ,"et al", pain:Clinical manual for nursing practice,Mosby St.Louis,MO.1989

6. Spinou A, Birring SS, An update on measurement and monitoring of cough: what are the important study endpoints? J Thorac Dis 2014;6(S7): 728-734.

7. $\mathrm{Ku} \mathrm{CM}$, Ong $\mathrm{BC}$, Postoperative nauseaand vomiting: a review of current literature. Singapore Med J. 2003;44:366-74. PubMedPMID: 14620731.

8. Stout DM, Bishop MJ, Dwersteg JF, Cullen BF, Correlation of endotracheal tube size with sore throat and hoarseness following general anesthesia, Anesthesiology 1987; 67 (3) ,419-21

9. Takekawa K, Yoshimi S, Kinoshita Y, Effects of intravenous lidocaine prior to intubation on postoperative airway symptoms, J Anesth. 2006; 20(1), 44-7

10.S.L.Basha, E.McCoy, R.Ullah, J.B.Kinsella, The efficacy of pharyngeal packing during routine nasal surgery - a prospective randomised controlled study, Anaesthesia, 2006;61,1161-1166

11.B.G.Fennessy, S.Mannion, J.B.Kinsella,P.O.Sullivan, The benefits of hypopharygeal packing in nasal surgery: a pilot study.Ir J Med Sci2011;2,180-183

12.Maruyama K, Sakai H, Miyazawa H, " et al”, Sore throat and hoarseness after total intravenous anaesthesia, Br J Anaesth 2004; 92(4), 541-3

13.Christensen AM, Willemoes-Larsen H, Lundby L, Jakobsen KB, Postoperative throat complaints after tracheal intubation, Br J Anaesth. 1994; 73(6), 786-7.

14.Somerville M, Karlsson JA, Richardson PS, The effects of local anaesthetic agents upon mucus secretion in the feline trachea in vivo. Pulm Pharacol 1990; 3(2), 93-101.

15.Hara K, Maruyama K, Effect of additives in lidocaine spray on postoperative sore throat, hoarseness and dysphagia after total intravenous anaesthesia Acta Anaesthesiol Scand 2005; 49(4), 463-7

16.Donnelly WH. Histopathology of endotracheal intubation, Arch Pathol. 1969; 88(5), 511-20

17.Hilding AC, Laryngotracheal damage during intratracheal anesthesia, Ann Otol Rhinol Laryngol, $1971 ; 80(4), 565-81$

18.Kessler TL, Mercer HJ, Zeiske JD, McCarthy DM, Dartt DA , Stimulation of goblet cell mucus secretion by activation of nerves in rat conjunctiva, Curr Eye Res 1995; 14(11), 985-92

19.Cormack RS, Lehane J, Difficult tracheal intubation in obstetrics, Anaesthesia 1984; 39(11), 110511 .

20.Shah MV, Mapleson WW, Sore throat after intubation of the trachea, Br J Anaesth,1984; 56(12),1337-41.

21.Monroe MC, Gravenstein N, Saga-Rumley S, Postoperative sore throat: effect of oropharyngeal airway in orotracheally intubated patients, Anesth Analg, 1990; 70(5), 512-6

22.Seegobin RD, Van Hasselt GL, Endotracheal cuff pressure and tracheal mucosal blood flow: endoscopic study of effects of four large volume cuffs. Br Med J. 1984; 288(6422), 965-8

23. Mandoe H, Nikolajsen L, Lintrup U, Jepsen D, Molgaard J, Sore throat after endotracheal intubation, Anesth Analg 1992; 74(6), 897-900 


\title{
Comparison of the effect of two pharyngeal packing methods (wet pack with saline and wet pack with lidocaine) on postoperative sore throat after nasal surgery
}

\author{
Hosseinzadeh $H^{1}$, Mohmmadi Pour Anvari $H^{2}$, kolahdouzan $\mathrm{kh}^{3}{ }^{*}$, Sheikhmonazzah $\mathrm{F}^{4}$ \\ ${ }^{1}$ Professor of Anesthesiology, faculty of medicine, Tabriz university of medical science \\ ,Tabriz, Iran \\ ${ }^{2}$ Associate professor of Anesthesiology, faculty of para medicine, Tabriz university of medical \\ science, Tabriz, Iran \\ ${ }^{3}$ Instructor of Anesthesiology ,faculty of para medicine, Tabriz university of medical \\ science, Tabriz, Iran \\ ${ }^{4}$ Resident of Anesthesiology, faculty of medicine ,Tabriz university of medical \\ Science, Tabriz, Iran \\ *Corresponding Author: Tabriz university of medical science, Tabriz, Iran \\ Email: kkolahdouzan@yahoo.com
}

\section{Abstract}

Background and Objective: Sore throat is a common and unpleasant complication of anesthesia which often occurs after the extubation. This study was conducted to compare the effects of two pharyngeal packing methods (wet pack with saline and wet pack with $1 \%$ of Lidocaine) on postoperative sore throat after the nasal surgery.

Materials and Methods: Sixty patients aged between 18-70 years with ASA I-II-III who were candidates for elective nasal surgery and categorized in two groups were enrolled in this double-blind randomized clinical trial. In the first group dampened gauze with $10 \mathrm{cc} / \mathrm{kg}$ was used for pharyngeal packing. Patients underwent general anesthesia with a similar method and after intubation, pharyngeal pack was placed with Magill forceps and in the end of operation before extubation was removed. Amount of sore throat, coughing, odynophagia, hoarseness, laryngeal spasm, nausea, and vomiting were assessed and compared after the extubation.

Results: There weren't any significant differences between groups in term of weight, height, sex, age, duration of surgery, and type of surgery $(p=0.194)$. Also there wasn't significant difference in sore throat between the lidocaine and placebo group.

Conclusions: There wasn't any significant difference in sore throat between two groups of Lidocaine and placebo.

Keywords: pharyngeal packing, nasal surgery, Lidocaine, sore throat 